УДК $546+54-161.6$

\title{
Орися БЕРЕЗНЮК
}

аспірант кафедри хімії та технологій, Волинський наиіональний університет імені Лесі Украӥнки, просп. Волі, 13, м. Луцьк, Україна, 43025

\section{Ірина ПЕТРУСЬ}

кандидат хімічних наук, старший лаборант кафедри хімії та технологій, Волинський національний університет імені Лесі Украӥнки, просп. Волі, 13, м. Луцьк, Украӥна, 43025

ORCID: 0000-0003-2527-6356

\section{Олександр СМІТЮХ}

кандидат хімічних наук, старший лаборант кафедри хімії та технологій, Волинський національний університет імені Лесі Українки, просп. Волі, 13, м. Луцьк, Україна, 43025, е-таіl: Smitiukh.Oleksandr@vnu.edu.ua

ORCID: 0000-0003-1632-5849

\section{Іван ОЛЕКСЕЮК}

доктор хімічних наук, професор, завідувач кафедри хімії та технологій, Волинський національний університет імені Лесі Украӥнки, просп. Волі, 13, м. Луцьк, Украӥна, 43025

ORCID: 0000-0001-7206-4351

Бібліографічний опис статті: Березнюк, О., Петрусь, І., Смітюх, О., Олексеюк, I. (2021). Склоутворення в квазіпотрійних системах $\mathrm{A}_{2}^{\mathrm{I}} \mathrm{S}-\mathrm{B}^{\mathrm{IV}} \mathrm{S}_{2}-\mathrm{C}_{2}^{\mathrm{V}} \mathrm{S}_{3}\left(\mathrm{~A}^{\mathrm{I}}-\mathrm{Cu}, \mathrm{Ag} ; \mathrm{B}^{\mathrm{IV}}-\mathrm{Ge}, \mathrm{Sn}, \mathrm{C}^{\mathrm{V}}-\mathrm{As}, \mathrm{Sb}\right)$. Проблеми хімї̈ та сталого розвитку, 4, 3-10, doi: https://doi.org/10.32782/pcsd-2021-4-1

$$
\begin{gathered}
\text { СКЛОУТВОРЕННЯ В КВАЗІПОТРІЙНИХ СИСТЕМАХ } \\
\mathrm{A}_{2}^{\mathrm{I}} \mathrm{S}-\mathrm{B}^{\mathrm{IV}} \mathrm{S}_{2}-\mathrm{C}_{2}^{\mathrm{V}} \mathrm{S}_{3}\left(\mathrm{~A}^{\mathrm{I}}-\mathrm{CU}, \mathrm{AG}^{\mathrm{N}} \mathbf{B}^{\mathrm{IV}}-\mathrm{GE}, \mathrm{SN}, \mathrm{C}^{\mathrm{V}}-\mathrm{AS}, \mathrm{SB}\right)
\end{gathered}
$$

Уперше встановлено межі областей склоутворення у квазіпотрійних системах $A_{2}^{I} S-B^{I V} S_{2}-C^{V} S_{2}\left(A^{I}-C u, A g\right.$; $\left.B^{I V}-G e, S n, C^{V}-A s, S b\right)$ на основі результатів рентгенофазового аналізу. Максимальна температура синтезу становила $1100 \mathrm{~K}$ із подальшим гартуванням ампул у 25-відсотковий водний розчин натрій хлориду з подрібненим льодом. Одержані склоподібні зразки становили темно-сірі та жовто-червоні блискучі монолітні сплави.

У досліджуваних германійумісних системах $A_{2}^{I} S-G e S_{2}-C_{2}^{V} S_{3}$ наявні неперервні області склоутворення на сторонах GeS $\mathrm{C}_{2} \mathrm{C}_{2} \mathrm{~S}_{3}$. Головним чинником є схильність Ge $S_{2}$, As $s_{2} S_{3}$ ma $\mathrm{Sb}_{2} \mathrm{~S}_{3}$ до склоутворення. За перерізом $A g_{2} \mathrm{~S}-\mathrm{GeS}$ y склоподібному стані отримуємо зразки з умістом $\mathrm{Ag} \mathrm{S}_{2}$ від 0 до 55 мол.\%. У квазібінарній системі $\mathrm{Ag}_{2} \mathrm{~S}-\mathrm{As} \mathrm{S}_{3}$ є область склоутворення в межах 0-70 мол.\% $\mathrm{Ag} \mathrm{g}_{2} \mathrm{~S}$. Максимальний уміст модифікатора Cu $\mathrm{S}$, який удалося ввести за умов збереження склоподібного стану, становить 10 та 15 мол.\% у системах Си, $S$ $\mathrm{GeS}_{2}-\mathrm{As}(\mathrm{Sb})_{2} \mathrm{~S}_{3}$ відповідно. Максимальний уміст $\mathrm{Ag}_{2} \mathrm{~S}$, щзо входить до складу скла в системах $\mathrm{Ag}_{2} \mathrm{~S}_{-} \mathrm{GeS} \mathrm{S}_{2}-\mathrm{As}(\mathrm{Sb})_{2} \mathrm{~S}_{3}$, становить 70 та 55 мол.\% відповідно.

У станумовмісних системах області склоутворення значно менші порівняно з аналогічними германійумісними, щуо пов 'язано з посиленням йонного складника хімічного зв'язку в разі заміни $G_{e} S_{2}$ на $\operatorname{Sn} S_{2}$. У квазіпотрійних системах $\mathrm{Cu}(\mathrm{Ag}){ }_{2} \mathrm{~S}-\mathrm{SnS} \mathrm{S}_{2}-\mathrm{Sb}_{2} \mathrm{~S}_{3}$ спостерігаємо лише дві області склоутворення, які розмішуються на стороні $\mathrm{SnS} \mathrm{S}_{2}-\mathrm{Sb}_{2} \mathrm{~S}_{3}$ : одна перебуває в області 17-23 мол.\% $\mathrm{Sb}_{2} \mathrm{~S}_{3}$, включно з 3 та 2 мол.\% Cu $\mathrm{S}, \mathrm{Ag} \mathrm{S}_{2} \mathrm{Sidnовід-}$ но, інша - 66-83 мол.\% $\mathrm{Sb}_{2} \mathrm{~S}_{3}$, максимальний уміст Cu, $\mathrm{S}$ ma Ag $\mathrm{Ag}_{2}$ становить 12 та 4 мол.\%. У системі Cи, S$\mathrm{SnS}_{2}-\mathrm{As} \mathrm{S}_{3}$ область склоутворення простягається від 76 до 100 мол.\% $\mathrm{As}_{2} \mathrm{~S}_{3}$, максимальний уміст Cu $\mathrm{S}$ становить 12 мол.\%. У системі $\mathrm{Ag}_{2} \mathrm{~S}-\mathrm{SnS} \mathrm{S}_{2}-\mathrm{As}_{2} \mathrm{~S}_{3}$ за перерізом $\mathrm{Ag} \mathrm{S}_{2}-\mathrm{As}_{2} \mathrm{~S}_{3}$ у склоподібному стані є зразки в межах 0-75 мол.\% $\mathrm{Ag} \mathrm{g}_{2} \mathrm{~S}$. На стороні $\mathrm{SnS}_{2}-\mathrm{As} \mathrm{S}_{2}$ концентраційного трикутника область склоутворення простягається від 78 до 100 мол. $\% \mathrm{As}_{2} \mathrm{~S}_{3}$.

Ключові слова: квазіпотрійна система, фазова діаграма, халькогенід, область склоутворення, рентгенофазовий аналіз. 


\section{Orysia BEREZNYUK}

Postgraduate Student at the Department of Chemistry and Technology, Lesya Ukrainka Volyn National University, 13 Voli Avenue, Lutsk, Ukraine, 43025

\section{Iryna PETRUS}

PhD in Chemistry, Head of Laboratory at the Department of Chemistry and Technology, Lesya Ukrainka Volyn National University, 13 Voli Avenue, Lutsk, Ukraine, 43025

ORCID: 0000-0003-2527-6356

\section{Oleksandr SMITIUKH}

PhD in Chemistry, Head of Laboratory at the Department of Chemistry and Technology, Lesya Ukrainka Volyn National University, 13 Voli Avenue, Lutsk, Ukraine, 43025

ORCID: 0000-0003-1632-5849

\section{Ivan OLEKSEYUK}

Doctor of Chemical Sciences, Professor, Head of the Department of Chemistry and Technology, Lesya Ukrainka Volyn National University, 13 Voli Avenue, Lutsk, Ukraine, 43025

ORCID: 0000-0001-7206-4351

To cite this article: Bereznyuk, O., Petrus, I., Smitiukh, O., Olekseiuk, I. (2021). Skloutvorennia v kvazipotriinykh systemakh $\mathrm{A}_{2}^{\mathrm{I}} \mathrm{S}-\mathrm{B}^{\mathrm{IV}} \mathrm{S}_{2}-\mathrm{C}_{2}^{\mathrm{V}} \mathrm{S}_{3}\left(\mathrm{~A}^{\mathrm{I}}-\mathrm{Cu}, \mathrm{Ag} ; \mathrm{B}^{\mathrm{IV}}-\mathrm{Ge}, \mathrm{Sn}, \mathrm{C}^{\mathrm{V}}-\mathrm{As}, \mathrm{Sb}\right)$ [Glass Formation in the Quasi-ternary Systems $\mathrm{A}_{2}^{\mathrm{I}} \mathrm{S}-\mathrm{B}^{\mathrm{IV}} \mathrm{S}_{2}-\mathrm{C}_{2}{ }_{2} \mathrm{~S}_{3}\left(\mathrm{~A}^{\mathrm{I}}-\mathrm{Cu}, \mathrm{Ag} ; \mathrm{B}^{\mathrm{IV}}-\mathrm{Ge}, \mathrm{Sn}, \mathrm{C}^{\mathrm{V}}-\mathrm{As}, \mathrm{Sb}\right)$ ]. Problems of Chemistry and Sustainable Development, 4, 3-10, doi: https://doi.org/10.32782/pcsd-2021-4-1

\section{GLAS FORMATION IN THE QUASI-TERNARY SYSTEMS A ${ }_{2}^{\mathrm{I}} \mathrm{S}-\mathrm{B}^{\mathrm{IV}} \mathbf{S}_{2}-\mathrm{C}_{2}^{\mathrm{V}} \mathrm{S}_{3}$ $\left(A^{\mathrm{I}}-\mathrm{CU}, \mathrm{AG} ; \mathrm{B}^{\mathrm{IV}}-\mathrm{GE}, \mathrm{SN}, \mathrm{C}^{\mathrm{V}}-\mathrm{AS}, \mathrm{SB}\right)$}

The boundaries of the glass formation areas of quasiternary systems $A_{2}^{I} S-B^{I V} S_{2}-C^{V} S_{3}\left(A^{I}-C u, A g ; B^{I V}-G e, S n\right.$, $\left.C^{V}-A s, S b\right)$ have been established by based on the results of X-ray phase analysis. Maximum synthesis temperature was $1100 \mathrm{~K}$, followed by quenching of the ampoules in $25 \%$ a solution of sodium chloride with crushed ice. The obtained glasses have been dark gray, yellow-red color monolithic alloys.

There are continuous bands of glass formation on the sides $G e S_{2}-C^{V} S_{3}$ in the studied germanium-containing systems $A^{I} S-G e S_{2}-C_{2}^{V} S_{3}$. The main factor is the tendency of $\mathrm{GeS}_{2}, A s_{2} S_{3}$ and $\mathrm{Sb}_{2} \mathrm{~S}_{3}$ to the glass formation. The content of $0-$

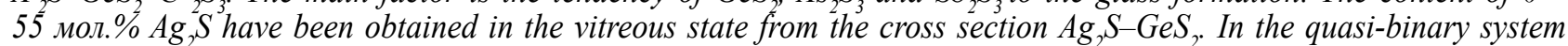
$\mathrm{Ag} \mathrm{S}_{2} \mathrm{As} \mathrm{S}_{3}$ there is a region of glass formation in the 0-70 mol.\% $\mathrm{Ag}$. $\mathrm{S}$. The maximum content of the modifier Cu, $\mathrm{S}$ that could be introduced while preserving the glassy state is 10 and 15 mol.\% in the systems $C u_{2} S-G e S,-A s(S b){ }_{2} S_{3}$. The maximum content of the $\mathrm{Ag} \mathrm{g}_{2} \mathrm{~S}$ that is part of the glass in the systems $\mathrm{Cu} \mathrm{S}_{2} \mathrm{G}-\mathrm{G}_{2}-\mathrm{As}(\mathrm{Sb})_{2} \mathrm{~S}_{3}$ state is 10 and $15 \mathrm{~mol} . \%$.

The areas of glass formation have been much smaller compared to similar germanium-containing in the statecontaining systems of the glassformation area, which is associated with the strengthening of the ionic component of the chemical bond by changing $\mathrm{GeS}_{2}$ to $\mathrm{SnS}$. We observe only two areas of glass formation in quasi-triple systems $\mathrm{Cu}(\mathrm{Ag})_{2} \mathrm{~S}-\mathrm{SnS} \mathrm{S}_{2}-\mathrm{Sb}_{2} \mathrm{~S}_{3}$ which are on the side $\mathrm{SnS} \mathrm{S}_{2}-\mathrm{Sb} \mathrm{S}_{2}$ : one in the area 17-23 mol.\% $\mathrm{Sb}_{2} \mathrm{~S}_{3}$, the maximum content of $\mathrm{Cu}, \mathrm{S}$ and $\mathrm{Ag} \mathrm{S}_{2}$ is 3 and $2 \mathrm{~mol} \%$; the other - 66-83 mol.\% $\mathrm{Sb}_{2} \mathrm{~S}_{3}$, the maximum content of $\mathrm{Cu} \mathrm{u}_{2} \mathrm{~S}$ and $\mathrm{Ag} \mathrm{S}_{2}$ is 12 and $4 \mathrm{~mol} \%$. In the system $\mathrm{Cu} \mathrm{S}_{2}-\mathrm{SnS}-\mathrm{As}_{2} \mathrm{~S}_{3}$ the region of glass formation state is 76-100 mol.\% $\mathrm{As} \mathrm{S}_{2}$, the maximum content of Cu $\mathrm{S}$ is 12 mol.\%. In the $A g_{2} S-S n S_{2}-A s_{2} S_{3}$ system, on the cross section of $A g_{2} S-A s_{2} S_{3}$, the region of glass formation state is 0-75 mol.\% $\mathrm{Ag}$ S. On the cross section of $\mathrm{SnS}_{2}-\mathrm{As}_{2} \mathrm{~S}_{3}$ the region of glass formation state is $78-100 \mathrm{~mol}_{2} \% \mathrm{As}_{2} \mathrm{~S}_{3}$.

Key words: quasi-ternary systems, phase diagram, chalcogenides, glass formation, X-ray phase analysis.

\section{1. Ветуп}

Зважаючи на стрімкий розвиток інфрачервоної фотоніки, актуальним є пошук функціональних середовищ для ефективного передання електромагнітного випромінювання широкого спектрального діапазону, розробка новітніх технологій мініатюризації оптоелектронної та фотонної техніки для різноманітних при- ладних застосувань (сенсори, оптичні волокна, резонатори, детектори, підсилювачі та перетворювачі сигналів, тощо). Одні з найбільш перспективних матеріалів - халькогенідні напівпровідникові стекла, які мають унікальну властивість - відмінну прозорість в інфрачервоному діапазоні спектра [1]. Зокрема, алмазоподібні напівпровідники типу $\mathrm{A}_{2}^{\mathrm{I}} \mathrm{B}^{\mathrm{IV}} \mathrm{S}_{3}\left(\mathrm{~A}^{\mathrm{I}}-\mathrm{Cu}, \mathrm{Ag}\right.$; 
$\left.\mathrm{B}^{\mathrm{IV}}-\mathrm{Ge}, \mathrm{Sn}\right)$ володіють цікавими фотоелектричними, акустооптичними і термоелектричними властивостями (Бабанлы, Юсибов \& Абишев, 1993; Cho et al, 2011; Marcano, Bracho, Rincon, Perez \& Nieves, 2000). Отже, встановлення областей склоутворення у системах $\mathrm{Cu}(\mathrm{Ag})_{2} \mathrm{~S}$ $\mathrm{Ge}(\mathrm{Sn}) \mathrm{S}_{2}-\mathrm{As}(\mathrm{Sb})_{2} \mathrm{~S}_{3} 3$ метою пошуку нових та більш перспективних матеріалів $\epsilon$ актуальним.

Слід зазначити, що вихідні компоненти $\mathrm{GeS}_{2}, \mathrm{As}(\mathrm{Sb})_{2} \mathrm{~S}_{3}$ є склоутворювачами.

Германій дисульфід має шарувату структуру, тому є цікавим у галузі оптоелектроніки. Згідно 3 (Виноградова, 1984) склоутворення в системі пов'язане 3 тим, що $\mathrm{GeS}_{2}$ є кристалохімічним аналогом однієї з модифікацій $\mathrm{SiO}_{2}$. Цікавою $\epsilon$ структура $\mathrm{GeS}_{2}$, яка складається 3 тетраедрів $\mathrm{GeS}_{4}$, що з'єднані вершинами (Кевшин, 2014). Слід зазначити, що температура склування цієї бінарної сполуки $є$ найвищою для всіх відомих халькогенідних стекол і становить 758 К (Борисова, Бычков \& Тверьянович, 1991).

Склоподібний $\mathrm{As}_{2} \mathrm{~S}_{3}$ легко отримати навіть в умовах охолодження в режимі вимкненої печі (Роусон, 1970). Завдяки електричним, оптичним i термічним властивостям він застосовується в лазерних технологіях, системах копіювання, сучасних пристроях зберігання та передання даних, голографічних елементах, оптичних фільтрах, нелінійних елементах (Паюк, Ліщинський, Стронський, Криськов, Губанова, Прібилова \& Влочек, 2011) Область склоутворення в системі As-S простягається від 5,4 до 45 ат.\% As (Flaschen, Pearson \& Northover, 1959)

Згідно 3 (Виноградова, 1984) аморфну оранжево-червону модифікацію $\mathrm{Sb}_{2} \mathrm{~S}_{3}$ можна отримати, використовуючи високу швидкість охолодження (473-523 К). Проте під час нагрівання отриманого скла до 723 К відбувається його повна кристалізація. Імовірно, можливість отримання $\mathrm{Sb}_{2} \mathrm{~S}_{3}$ в склоподібному стані пов'язана 3 особливістю структури сполуки, a саме зі здатністю до зниження к.ч. Sb.

Аналіз наукової літератури показав, що склоподібні зразки перерізу $\mathrm{Ag}_{2} \mathrm{~S}-\mathrm{GeS}_{2}$ можуть бути отримані в інтервалі 45-100 мол.\% $\mathrm{GeS}_{2}$ (Kamitsos, Kapoutsis, Chryssikos, Taillades, Pradel \& Ribes, 1994; El Mkami, Deroide, Zanchetta, Rumori \& Abidi, 1996). У роботі (Борисова, 1983) наведено відомості про склоутворення, згідно з якими під час загартування від 1170 К наявні стекла на квазібінар- них перерізах $\mathrm{Cu}_{2} \mathrm{~S}\left(\mathrm{Ag}_{2} \mathrm{~S}\right)-\mathrm{As}_{2} \mathrm{~S}_{3}$. Досліджено, що під час комбінації різних режимів гарту в системі $\mathrm{GeS}_{2}-\mathrm{As}_{2} \mathrm{~S}_{3}$ область склоутворення становить 0-62,48 мол.\% германій дисульфіду (Виноградова, 1984). Склоподібні зразки в системі Sn-As-S (Виноградова, 1984) отримано на великих швидкостях охолодження від 1170 К. При цьому в скло вдається ввести до 2,5 ат.\% $\mathrm{Sn}$. Під час сплавляння бінарних $\mathrm{GeS}_{2}$ та $\mathrm{Sb}_{2} \mathrm{~S}_{3}$ вакуумним синтезом за максимальної температури 970-1270 К отримано стекла в системі $\mathrm{GeS}_{2}-\mathrm{Sb}_{2} \mathrm{~S}_{3}$ (Виноградова, 1984).

Склоутворення в аналогічних квазіпотрійних системах із селеном наведено в літературних джерелах (Климович, Змій \& Олексеюк, 2013; Климович, Змій \& Олексеюк, 2007). Згідно 3 (Климович, Змій \& Олексеюк, 2013) у квазіпотрійній системі $\mathrm{Cu}_{2} \mathrm{Se}-$ $\mathrm{SnSe}_{2}-\mathrm{As}_{2} \mathrm{Se}_{3}$ склоподібними виявилися зразки: у системах $\mathrm{SnSe}_{2}-\mathrm{As}_{2} \mathrm{Se}_{3}$ та $\mathrm{Cu}_{2} \mathrm{Se}-$ $\mathrm{As}_{2} \mathrm{Se}_{3}$ до 55 мол. \% $\mathrm{SnSe}_{2}$ та 45 мол.\% $\mathrm{Cu}_{2} \mathrm{Se}$ відповідно; на перерізі $\mathrm{Cu}_{2} \mathrm{SnSe}_{3}-\mathrm{As}_{2} \mathrm{Se}_{3}$ при вмісті $\mathrm{As}_{2} \mathrm{Se}_{3}$ більше 65 мол.\%. Область склоутворення у системі $\mathrm{Cu}_{2} \mathrm{Se}-\mathrm{GeSe}_{2}-\mathrm{As}_{2} \mathrm{Se}_{3}$ прилягає до квазіподвійної системи $\mathrm{GeSe}_{2}-\mathrm{As}_{2} \mathrm{Se}_{3}$, суттєво розширюючись (до 40 мол.\% арсен(III) селеніду) (Климович, Змій \& Олексеюк, 2007).

Із вищенаведеної інформації можна прогнозувати значні області склоутворення в квазіпотрійних системах $\mathrm{Cu}(\mathrm{Ag})_{2} \mathrm{~S}-\mathrm{Ge}(\mathrm{Sn})$ $\mathrm{S}_{2}-\mathrm{As}(\mathrm{Sb})_{2} \mathrm{~S}_{3}$.

\section{2. Експериментальна частина}

Склоподібні напівпровідникові зразки синтезували 3 елементарних речовин високого ступеня чистоти (мідь, срібло, германій, олово, сурма та сірка) та попередньо синтезованого арсен (III) сульфіду. Синтез проводили у вакуумованих до залишкового тиску $1,33 \cdot 10^{-2}$ Па кварцових контейнерах. Режим синтезу обирали відповідно до фізико-хімічних властивостей компонентів скла та діаграм стану обмежувальних сторін. Так, склоподібні зразки систем нагрівали зі швидкістю $20 \mathrm{~K} /$ год до 1100 Кізвитримкамивпродовж 24 годза температур 670 та 870 К для зв'язування сірки. За максимальної температуризразки витримували 10 год.

Щоб зберегти визначену структуру скла, вибирали швидкий режим охолодження: ампули зі сплавами гартували у 25-відсотковий водний розчин натрій хлориду з подрібненим льодом. Для запобігання розбризкування роз- 
плаву в процесі гартування, а також для зменшення втрат на конденсацію парової фази стінками ампул використовували термостатування шнуровим азбестом.

Аморфність отриманого зразка контролювали візуально за характерним для скла зломом та за допомогою даних рентгендифрактометричних досліджень (ДРОН 4-13, $\mathrm{CuK}_{\alpha}$ випромінювання, діапазон кутів $2 \theta=10 \div 90^{\circ}$, крок $0,05^{\circ}$, експозиція - 2 с). На всіх дифрактограмах склоподібних зразків спостерігали «галло», відсутність піків свідчить про невпо- рядкованість атомів на відстані нанометричного характеру (Фунтиков, 1996).

\section{3. Результати та їх обговорення}

За результатами дослідження склоподібних зразків установлено, що найбільші області склоутворення існують у квазіпотрійних системax $\mathrm{Ag}_{2} \mathrm{~S}-\mathrm{GeS}_{2}-\mathrm{As}(\mathrm{Sb})_{2} \mathrm{~S}_{3}$ (рис. 1). Одна 3 причин - вихідні фази $\mathrm{GeS}_{2}, \mathrm{As}_{2} \mathrm{~S}_{3}$ та $\mathrm{Sb}_{2} \mathrm{~S}_{3}$, які $\epsilon$ склоутворювачами.

Як бачимо, максимальний уміст $\mathrm{Ag}_{2} \mathrm{~S}$, що входить до складу скла в цих системах, становить 70 та 55 мол.\% відповідно. Халькогенід
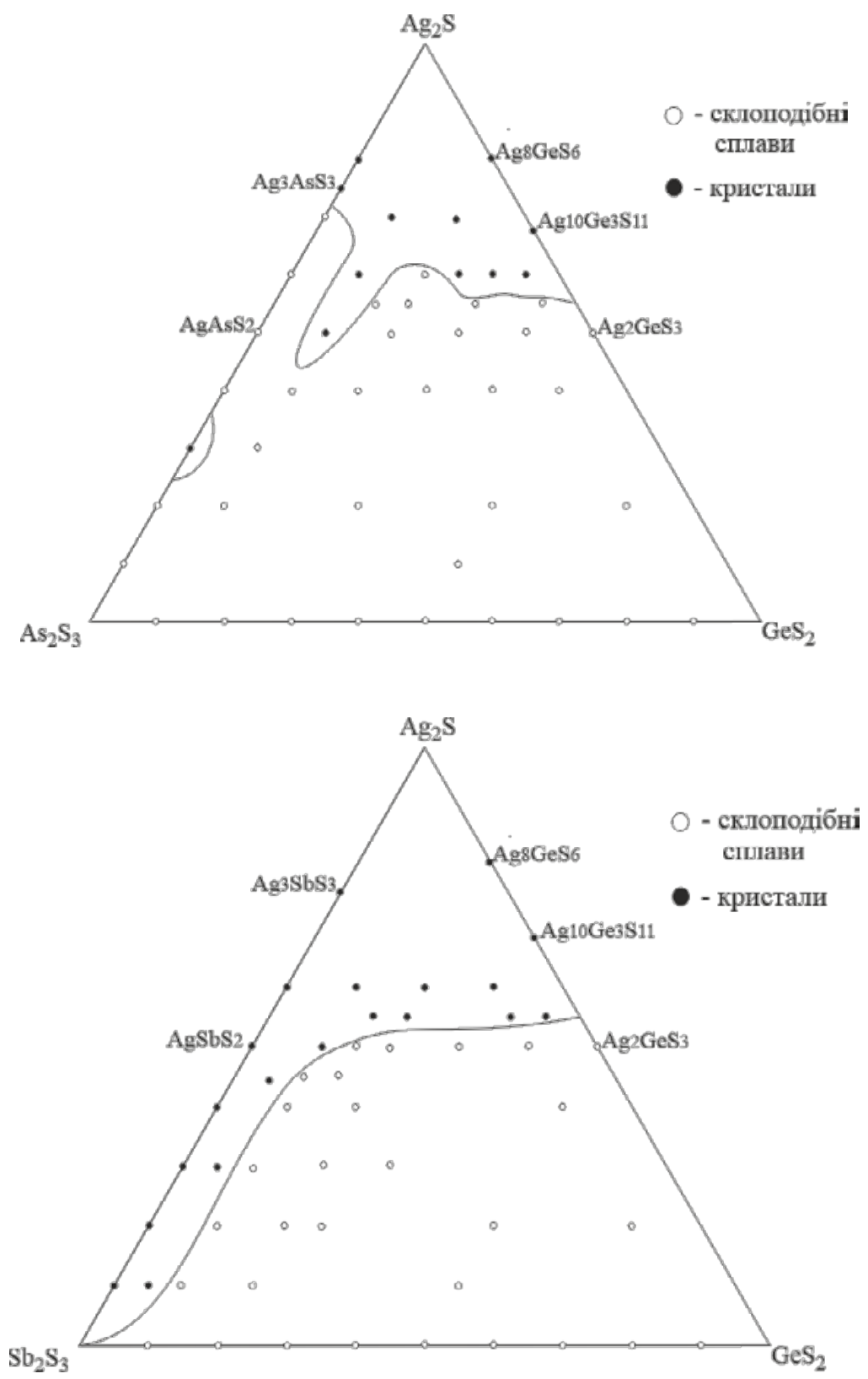

Рис. 1. Області склоутворення в системах $\mathrm{Ag}_{2} \mathrm{~S}-\mathrm{GeS}_{2}-\mathrm{As}(\mathrm{Sb})_{2} \mathrm{~S}_{3}$ 


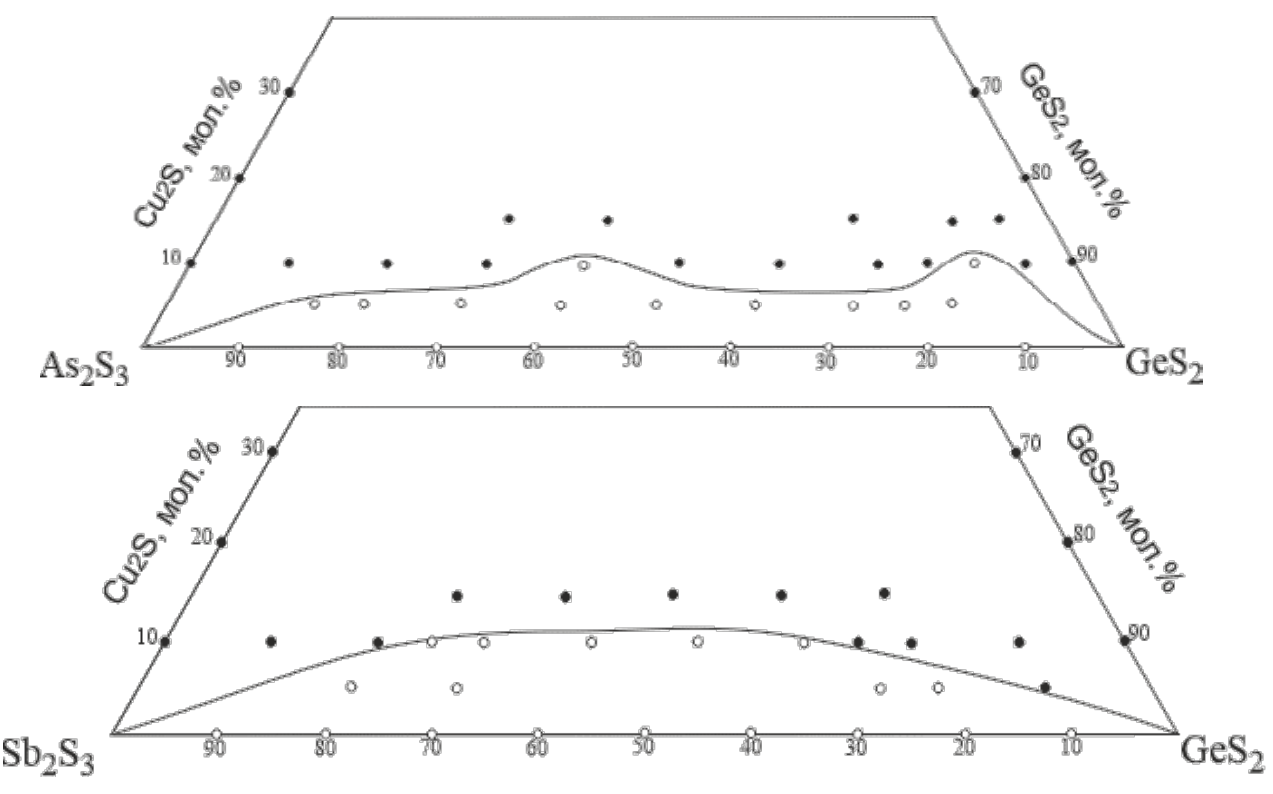

Рис. 2. Області склоутворення в системах $\mathrm{Cu}_{2} \mathrm{~S}-\mathrm{GeS}_{2}-\mathrm{As}(\mathrm{Sb})_{2} \mathrm{~S}_{3}$

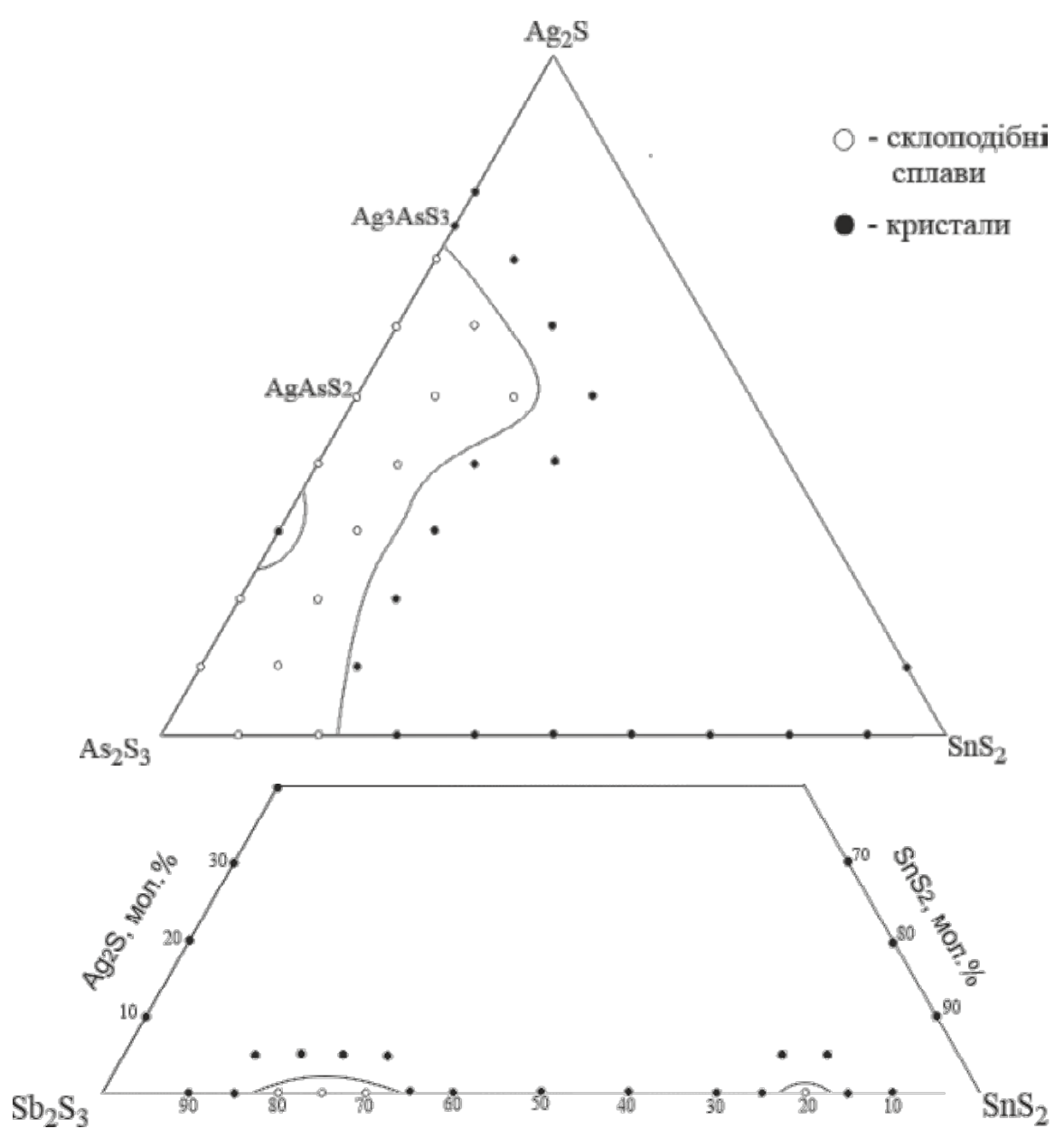

Рис. 3. Області склоутворення в системах $\operatorname{Ag}_{2} \mathrm{~S}-\mathrm{SnS}_{2}-\mathrm{As}(\mathrm{Sb})_{2} \mathrm{~S}_{3}$ 


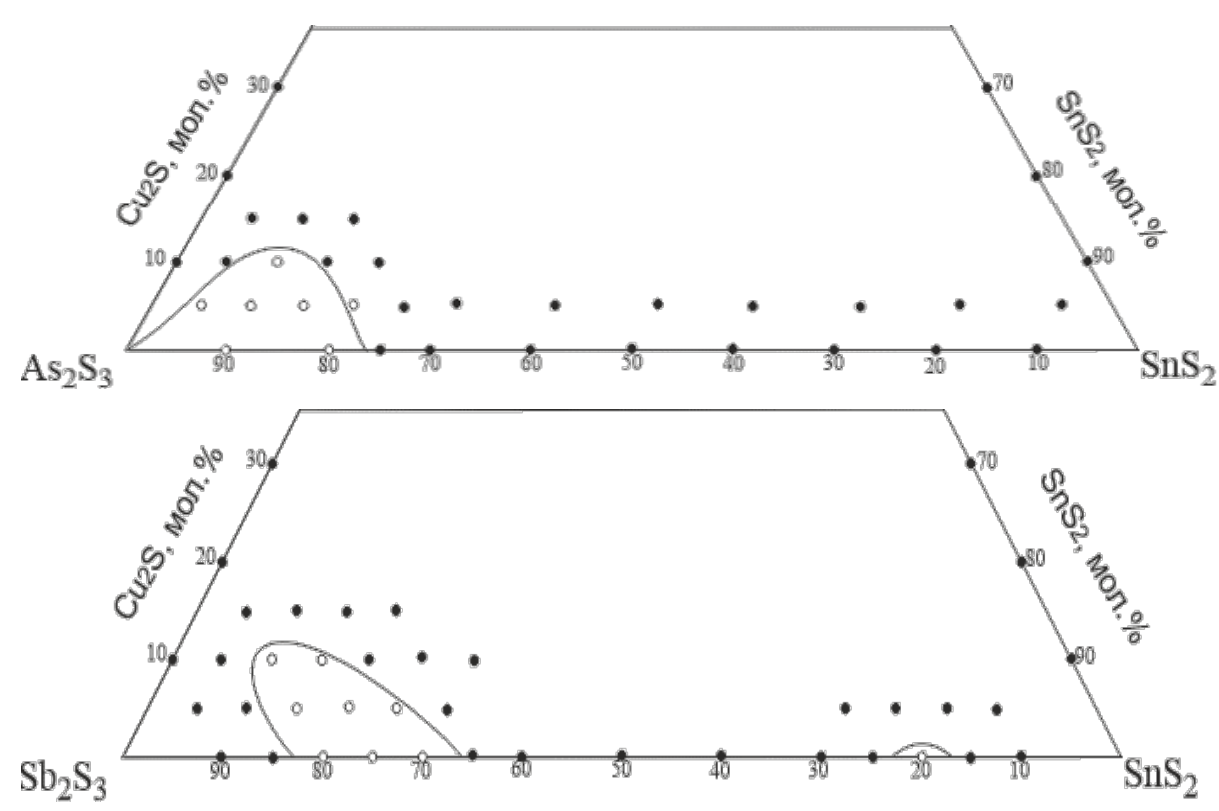

Рис. 4. Області склоутворення в системах $\mathrm{Cu}_{2} \mathrm{~S}-\mathrm{SnS}_{2}-\mathrm{As}(\mathrm{Sb})_{2} \mathrm{~S}_{3}$

$\mathrm{Ag}_{2} \mathrm{GeS}_{3}$ є склом, а одержати $\mathrm{Ag}_{10} \mathrm{Ge}_{3} \mathrm{~S}_{11}$ в аморфному стані складніше. Це пояснюється відсутністю структурно-хімічної основи у вигляді сітки по-різному з'єднаних тетраедрів $\left[\mathrm{GeS}_{4}\right]$. Розчленування структурної сітки у разі збільшення вмісту срібла сприяє значному зростанню іонної провідності, як це $є 3 \mathrm{Ag}_{8} \mathrm{GeS}_{6}$ (Ковач, Кохан \& Ворошилов, 1993). $\mathrm{Ag}_{8} \mathrm{GeS}_{6}$ при кімнатній температурі має змішану іонно-електронну провідність і переходить у суперіонний стан лише під час переходу у високотемпературну модифікацію, що характерно для більшості сполук родини аргіродитів (Кохан, 1996). Наявність значної кількості дефектних позицій i значно розшита структурна сітка створюють сприятливі умови для міграції іонів і можуть бути причиною високої іонної провідності в $\mathrm{Ag}^{+}$-іонах у сполуці $\mathrm{Ag}_{10} \mathrm{Ge}_{3} \mathrm{~S}_{11}$ уже при кімнатній температурі (Виноградова, 1984).

Область склоутворення на обмежувальній стороні $\mathrm{Ag}_{2} \mathrm{~S}-\mathrm{As}_{2} \mathrm{~S}_{3}$ розташована в інтервалі 0-70 мол.\% $\mathrm{Ag}_{2} \mathrm{~S}$. Одержані результати добре корелюють із літературними джерелами (Liu Jun, Videau, Tanguy, Portier \& Reau, 1988).

Результати визначення областей склоутворення у системах $\mathrm{Cu}_{2} \mathrm{~S}-\mathrm{GeS}_{2}-\mathrm{As}(\mathrm{Sb})_{2} \mathrm{~S}_{3}$ представлено на рис. 2.

Область склоутворення перетинає концентраційний трикутник лише по перерізу $\mathrm{GeS}_{2}-\mathrm{As}(\mathrm{Sb})_{2} \mathrm{~S}_{3}$. Положення атомів $\mathrm{Ge}, \mathrm{As}, \mathrm{Sb}$, $\mathrm{S}$ в Періодичній системі визначає майже повну відсутність у склі як іонного, так і металіч- ного складника хімічного зв'язку, що визначає область склоутворення (Борисова, 1983).

Максимальний уміст $\mathrm{Cu}_{2} \mathrm{~S}$, який удалося ввести в склад скла, не перевищує 10 та 15 мол.\% у системах $\mathrm{Cu}_{2} \mathrm{~S}-\mathrm{GeS}_{2}-\mathrm{As}(\mathrm{Sb})_{2} \mathrm{~S}_{3}$ відповідно. Відомості про склоутворення в обмежувальних системах $\mathrm{Cu}_{2} \mathrm{~S}-\mathrm{As}(\mathrm{Sb})_{2} \mathrm{~S}_{3}$ відсутні. Відповідно до результатів рентгенофазового аналізу за вибраного режиму гарту всі зразки мають яскраво виражений полікристалічний характер.

Області склоутворення в станумовмісних системах значно менші порівняно 3 аналогічними германійумісними. Це пояснюється тим, що $\mathrm{SnS}_{2}$ має шарувату структуру і що в межах однієї атомної площини між атомами $\mathrm{Sn}$ та $\mathrm{S}$ виникає сильний іонно-ковалентний зв'язок. Аналіз літературних джерел показав, що безпосередньо $\mathrm{SnS}_{2}$, на відміну від $\mathrm{GeS}_{2}$, у склоподібному стані не отримано. На нашу думку, це також позначається на величині області існування стекол.

$\mathrm{У}$ системі $\mathrm{Ag}_{2} \mathrm{~S}-\mathrm{SnS}_{2}-\mathrm{As}_{2} \mathrm{~S}_{3}$ (рис. 3) по переpiзу $\mathrm{Ag}_{2} \mathrm{~S}-\mathrm{As}_{2} \mathrm{~S}_{3}$ в склоподібному стані наявні зразки в межах 0-75 мол.\% $\mathrm{Ag}_{2} \mathrm{~S}$. На стороні $\mathrm{SnS}_{2}-\mathrm{As}_{2} \mathrm{~S}_{3}$ концентраційного трикутника область склоутворення простягається від 78 до 100 мол. $\% \mathrm{As}_{2} \mathrm{~S}_{3}$.

В аналогічній стибійумісній системі $\mathrm{Ag}_{2} \mathrm{~S}-$ $\mathrm{SnS}_{2}-\mathrm{Sb}_{2} \mathrm{~S}_{3}$ (рис. 3) спостерігаємо дві області склоутворення, які розміщуються на стороні $\mathrm{SnS}_{2}-\mathrm{Sb}_{2} \mathrm{~S}_{3}$ : одна мститься в області 17-23 мол.\% $\mathrm{Sb}_{2} \mathrm{~S}_{3}$, інша - 66-83 мол.\% $\mathrm{Sb}_{2} \mathrm{~S}_{3}$ (включно з 2 мол.\% та 4 мол.\%. $\mathrm{Ag}_{2} \mathrm{~S}$ відповідно). 
Відповідно до результатів рентгенофазового аналізу в системі $\mathrm{Cu}_{2} \mathrm{~S}-\mathrm{SnS}_{2}-\mathrm{As}_{2} \mathrm{~S}_{3}$ (рис. 4) область склоутворення локалізована на перерізі $\mathrm{SnS}_{2}-\mathrm{As}_{2} \mathrm{~S}_{3}$ в межах 76-100 мол.\% $\mathrm{As}_{2} \mathrm{~S}_{3}$, максимальний уміст $\mathrm{Cu}_{2} \mathrm{~S}$ становить 12 мол.\%.

Наобмежувальній стороні $\mathrm{SnS}_{2}-\mathrm{Sb}_{2} \mathrm{~S}_{3}$ концентраційного трикутника $\mathrm{Cu}_{2} \mathrm{~S}-\mathrm{SnS}_{2}-\mathrm{Sb}_{2} \mathrm{~S}_{3}$ (рис. 4) спостерігаємо такі дві області склоутворення: $17-23$ мол.\% $\mathrm{Sb}_{2} \mathrm{~S}_{3}$ (при вмісті 3 мол. $\% \mathrm{Cu}_{2} \mathrm{~S}$ ), 66-83 мол.\% $\mathrm{Sb}_{2} \mathrm{~S}_{3}$ (при вмісті 12 мол. $\% \mathrm{Cu}_{2} \mathrm{~S}$ ).

\section{4. Висновки}

Таким чином, за допомогою результатів рентгенофазового аналізу встановлено межі областей склоутворення у 8 квазіпотрійних системах. Варто зазначити, що більшість зразків систем $\mathrm{Ag}_{2} \mathrm{~S}-\mathrm{GeS}_{2}-\mathrm{As}(\mathrm{Sb})_{2} \mathrm{~S}_{3}$ - стекла, що пояснюється природою вихідних бінарних компонентів, як-от $\mathrm{GeS}_{2}, \mathrm{As}(\mathrm{Sb})_{2} \mathrm{~S}_{3}, \epsilon$ склоутворювачами. Також установлено, що по переpiзу $\mathrm{Ag}_{2} \mathrm{~S}-\mathrm{As}_{2} \mathrm{~S}_{3}$ в склоподібному стані існують зразки в межах 0-75 мол.\% $\mathrm{Ag}_{2} \mathrm{~S}$. В обмежувальних системах $\mathrm{Cu}_{2} \mathrm{~S}-\mathrm{C}_{2}{ }_{2} \mathrm{~S}_{3}$ та $\mathrm{Ag}_{2} \mathrm{~S}-\mathrm{Sb}_{2} \mathrm{~S}_{3}$ за умов вибраного режиму гарту стекла не утворюються.

Відомості про межі існування стекол у квазіпотрійних системах можуть бути використані як довідковий матеріал у галузі напівпровідникового матеріалознавства, що дозволить проводити цілеспрямований синтез нових матеріалів із заздалегідь заданими властивостями.

\section{ЛІТЕРАТУРА:}

1. Шпотюк М.В. Фізичні особливості радіаційно-структурної модифікації ковалентно-сіткового скла As-S : дис. ... док. фіз.-мат. наук : 01.04.07. Львів, 2018. 345 с.

2. Бабанлы М.Б., Юсибов Ю.А., Абишев В.Т. Трехкомпонентные халькогениды на основе меди и серебра. Баку : БГУ, 1993. 342 с.

3. Cho J.Y., Shi X., Salvador J.R., Meisner G.P., Yang J. et al. Thermoelectric properties and investigations of low thermal conductivity in Ga-doped $\mathrm{Cu}_{2} \mathrm{GeSe}_{3}$. Physical Review B. 2011. Vol. 84. № 8. Doi : 10.1103/PhysRevB.84.085207

4. Marcano G., Bracho D.B., Rincon C., Perez G.S., Nieves L. On the temperature dependence of the electrical and optical properties of $\mathrm{Cu}_{2} \mathrm{GeSe}_{3}$. Journal of Applied Physics. 2000. Vol. 88. P. 822-828.

5. Виноградова Г.З. Стеклообразование и фазовые равновесия в халькогенидных системах. Москва : Наука, 1984. $238 \mathrm{c}$.

6. Кевшин А.Г. Особливості структури халькогенідних стекол на базі $\mathrm{GeX}_{2}(\mathrm{X}=\mathrm{S}, \mathrm{Se})$. Фізика і хімія твердого тіла. 2014. Т. 15. № 4. С. 682-688.

7. Борисова З.У., Бычков Е.А., Тверьянович Ю.С. Взаимодействие металлов с халькогенидными стеклами : монография. Ленинград, 1991. 252 с.

8. Роусон Г. Неорганические стеклообразующие системы. Москва : Мир, 1970. 270 с.

9. Паюк О., Ліщинський І., Стронський О., Криськов Ц., Губанова А., Прібилова Г., Влочек М. Властивості стекол $\mathrm{As}_{2} \mathrm{~S}_{3}$ легованих марганцем: калориметричні дослідження та Раманівська спектроскопія. Фізика і хімія твердого тіла. 2011. Т. 12. № 3. C. 594-597.

10. Flaschen S.S., Pearson A.D., Northover W.R. Low-melting inorganic glasses with high melt fluidities below $400^{\circ}$. J. Amer. Ceram. Soc. 1959. Vol. 42. № 9. P. 450.

11. Kamitsos E.I., Kapoutsis J.A., Chryssikos G.D., Taillades G., Pradel A., Ribes M. Structure and Optical Conductivity of Silver Thiogermanate Glasses. J. Solid State Chem. 1994. Vol. 112. № 2. P. 255-261. Doi : $10.1006 /$ jssc.1994.1301.

12. El Mkami H., Deroide B., Zanchetta J.V., Rumori P., Abidi N. Electron paramagnetic resonance study of $\mathrm{Mn}^{2+}$ and $\mathrm{Cu}^{2+}$ spin probes in $\left(\mathrm{Ag}_{2} \mathrm{~S}\right)_{\mathrm{x}}\left(\mathrm{GeS}_{2}\right)_{1-\mathrm{x}}$ glasses. J. Non-Cryst. Solids. 1996. Vol. 208. № 1-2. P. 21-28. Doi: 10.1016/S0022-3093(96)00509-1.

13. Борисова 3.У. Халькогенидные полупроводниковые стекла. Ленинград : Ленингр. ун-т, 1983. 344 с.

14. Климович О.С., Змій О.Ф., Олексеюк І.Д. Фазові рівноваги та склоутворення в системі $\mathrm{Cu}_{2} \mathrm{Se}-\mathrm{SnSe}_{2}-$ $\mathrm{As}_{2} \mathrm{Se}_{3}$. Наук вісн. СНУ імені Лесі Украӥнки. Хімічні науки. 2013. № 23. С. 89-94.

15. Климович О.С., Змій О.Ф., Олексеюк І.Д. Склоутворення в системі $\mathrm{Cu}_{2} \mathrm{Se}-\mathrm{GeSe}_{2}-\mathrm{As}_{2} \mathrm{Se}_{3}$. Наук. вісн. ВДУ імені Лесі Українки. Хімічні науки. 2007. № 15. С. 14-18.

16. Фунтиков В.А. К вопросу о строении стёкол и физико-химическом анализе стеклообразных систем. Физика и химия стекла. 1996. Вып. 22. № 3. С. 279-285.

17. Ковач С.К., Кохан А.П., Ворошилов Ю.В. Электрохимическое поведение $\mathrm{Ag}_{8} \mathrm{GeS}_{6}$ и $\mathrm{Ag}_{8} \mathrm{GeSe}_{6} . У_{\kappa p}$. хим. журн. 1993. Вып. 59. № 4. С. 396-398.

18. Кохан О.П. Взаємодія в системах $\mathrm{Ag}_{2} \mathrm{X}-\mathrm{B}^{\mathrm{IV}} \mathrm{X}_{2}\left(\mathrm{~B}^{\mathrm{IV}}-\mathrm{Si}, \mathrm{Ge}, \mathrm{Sn} ; \mathrm{X}-\mathrm{S}, \mathrm{Se}\right)$ і властивості сполук : автореф. дис. ... канд. хім. наук : 02.00.01. Ужгород, 1996. $21 \mathrm{c}$.

19. Liu Jun, Videau J. J., Tanguy B., Portier J., Reau J. M. Investigation on glass in the As-Ag-S system. Mater. Res. Bull. 1988. Vol. 23. P. 1315-1320. 


\section{REFERENCES:}

1. Shpotyuk, M.V. (2018). Fizychni osoblyvosti radiatsiino-strukturnoi modyfikatsii kovalentno-sitkovoho skla As-S [Physical peculiarities of radiation-structural modification of As-S covalent-network glass] Doctor's thesis. Lviv [in Ukrainian].

2. Babanly, M.B., Yusibov, Yu.A., Abishev, V.T. (1993) Trekhkomponentnyye khalkogenidy na osnove medi i serebra [Three-component chalcogenides based on copper and silver]. Baku [in Russian].

3. Cho, J.Y., Shi, X., Salvador, J.R., Meisner, G.P., Yang, J. et al. (2011) Thermoelectric properties and investigations of low thermal conductivity in Ga-doped $\mathrm{Cu}_{2} \mathrm{GeSe}_{3}$. Physical Review B, Vol. 84. № 8 [in English].

4. Marcano, G., Bracho, D.B., Rincon, C., Perez, G.S., Nieves, L. (2000) On the temperature dependence of the electrical and optical properties of $\mathrm{Cu}_{2} \mathrm{GeSe}_{3}$. Journal of Applied Physics, Vol. 88. P.822-828 [in English].

5. Vinogradova, G.S. (1984). Stekloobrazovaniye i fazovyye ravnovesiya $v$ khalkogenidnykh sistemakh [Glass-formation and Phase Equlibria in Chalcogenide Systems]. Moscow, Nauka [in Russian].

6. Kevshyn, A.H. (2014) Osoblyvosti struktury khalkohenidnykh stekol na bazi $\mathrm{GeX}_{2}(\mathrm{X}=\mathrm{S}, \mathrm{Se})$ [Features of the structure of chalcogenide glasses based on $\left.\mathrm{GeX}_{2}(\mathrm{X}=\mathrm{S}, \mathrm{Se})\right]$ Physics and Chemistry of Solid State, Vol. 15, № 4, P. 682-688 [in Ukrainian].

7. Borisova, Z.U., Bychkov, E.A., Tverianovich, Yu.S. (1991) Vzaimodeistviye metallov s khalkogenidnymi steklami [Interaction of metals with chalcogenide glasses]. Leningrad [in Russian].

8. Rouson, G. (1970). Neorganicheskiye stekloobrazuyushchiye sistemy [Inorganic glass-forming systems]. Moskow, Mir [in Russian].

9. Paiuk, O., Lishchynskyi, I., Stronskyi, O., Kryskov, Ts., Hubanova, A., Pribylova, H., Vlochek, M. (2011) Vlastyvosti stekol $\mathrm{As}_{2} \mathrm{~S}_{3}$ lehovanykh marhantsem: kalorymetrychni doslidzhennia ta Ramanivska spektroskopiia [Properties $\mathrm{As}_{2} \mathrm{~S}_{3}$ Glasses Doped with Manganese: Calorimetrical Study and Raman Spectroscopy] Physics and Chemistry of Solid State, Vol. 12, № 3, P. 594-597 [in Ukrainian].

10. Flaschen, S.S., Pearson, A.D., Northover, W.R. (1959) Low-melting inorganic glasses with high melt fluidities below $400^{\circ}$. J. Amer. Ceram. Soc., Vol. 42. № 9, P.450 [in English].

11. Kamitsos, E.I., Kapoutsis, J.A., Chryssikos, G.D., Taillades, G., Pradel, A., Ribes, M. (1994) Structure and Optical Conductivity of Silver Thiogermanate Glasses. J. Solid State Chem., Vol. 112. № 2. P. 255-261 [in English].

12. El Mkami, H., Deroide, B., Zanchetta, J.V., Rumori, P., Abidi, N. (1996) Electron paramagnetic resonance study of $\mathrm{Mn}^{2+}$ and $\mathrm{Cu}^{2+}$ spin probes in $\left(\mathrm{Ag}_{2} \mathrm{~S}\right)_{\mathrm{x}}\left(\mathrm{GeS}_{2}\right)_{1-\mathrm{x}}$ glasses. J. Non-Cryst. Solids., Vol. 208. № 1-2. P. 21-28 [in English].

13. Borisova, Z.U. (1983) Khalkogenidnyye poluprovodnikovyye stekla [Chalcogenide semiconductor glasses]. Leningrad: Leningrad. un-t [in Russian].

14. Klymovych, O.S., Zmiy, O.F, Olekseyuk, I. D. (2013) Fazovi rivnovahy ta skloutvorennia v systemi $\mathrm{Cu}_{2} \mathrm{Se}_{-} \mathrm{SnSe}_{2}-$ $\mathrm{As}_{2} \mathrm{Se}_{3}$ [Phase equilibria and glass formation in the $\mathrm{Cu}_{2} \mathrm{Se}_{-} \mathrm{SnSe}_{2}-\mathrm{As}_{2} \mathrm{Se}_{3}$ system] Lesya Ukrainka Eastern European National Univ. Sci. Bull. Chemistry series, № 23, P. 89-94 [in Ukrainian].

15. Klymovych, O.S., Zmiy, O.F, Olekseyuk, I. D. (2007) Skloutvorennia v systemi $\mathrm{Cu}_{2} \mathrm{Se}-\mathrm{GeSe}_{2}-\mathrm{As}_{2} \mathrm{Se}_{3}[\mathrm{Glass}$ formation in the $\mathrm{Cu}_{2} \mathrm{Se}-\mathrm{GeSe}_{2}-\mathrm{As}_{2} \mathrm{Se}_{3}$ system]. Lesya Ukrainka Volyn State Univ. Sci. Bull. Chemistry series, № 15, P. 14-18 [in Ukrainian].

16. Funtykov, V.A. (1996) K voprosu o stroyenii stekol i fiziko-khimicheskom analize stekloobraznykh sistem [On the question of the Structure of Glasses and physicochemical Analysis of vitreous systems] Glass Physics and Chemistry, Vol. 22, № 3, P. 279-285 [in Russian].

17. Kovach, S.K., Kokhan, A.P., Voroshylov, Yu.V.(1993) Эlektrokhymycheskoe povedenye $\mathrm{Ag}_{8} \mathrm{GeS}_{6} \mathrm{y} \mathrm{Ag}_{8} \mathrm{GeSe}_{6}[\mathrm{Elec}$ trochemical behavior $\mathrm{Ag}_{8} \mathrm{GeS}_{6}$ and $\mathrm{Ag}_{8} \mathrm{GeSe}_{6}$ ] Ukrainian Chemistry Journal, Vol. 59, № 4, P. 396-398 [in Russian].

18. Kokhan, O.P. (1996) Vzaiemodiia v systemakh $\mathrm{Ag}_{2} \mathrm{X}-\mathrm{B}^{\mathrm{IV}} \mathrm{X}_{2}\left(\mathrm{~B}^{\mathrm{IV}}-\mathrm{Si}, \mathrm{Ge}, \mathrm{Sn} ; \mathrm{X}-\mathrm{S}, \mathrm{Se}\right)$ i vlastyvosti spoluk [Interaction in systems $\mathrm{Ag}_{2} \mathrm{X}-\mathrm{B}^{\mathrm{IV}} \mathrm{X}_{2}\left(\mathrm{~B}^{\mathrm{IV}}-\mathrm{Si}, \mathrm{Ge}, \mathrm{Sn} ; \mathrm{X}-\mathrm{S}, \mathrm{Se}\right)$ and properties of compounds]. Extended abstract of candidate's thesis. Uzhhorod [in Ukrainian].

19. Liu Jun, Videau, J. J., Tanguy, B., Portier, J., Reau, J. M. (1988) Investigation on glass in the As-Ag-S system. Mater. Res. Bull., №23, P. 1315-1320 [in English]. 